\title{
DETERMINATION OF FLUOXETINE HYDROCHLORIDE VIA ION-PAIR COMPLEXATION WITH ALIZARIN RED S
}

\author{
IOANA CLEMENTINA CONSTANTINESCU ${ }^{1 *}$, ALEXANDRA FILARETA NEAGU ${ }^{1}$ \\ and VALENTINA UIVAROSI ${ }^{2}$
}

'Department of Analytical Chemistry, "Carol Davila" University of Medicine and Pharmacy, Faculty of Pharmacy, Bucharest, Romania

${ }^{2}$ Department of General and Inorganic Chemistry, "Carol Davila" University of Medicine and Pharmacy, Faculty of Pharmacy, Bucharest, Romania

\begin{abstract}
Two UV-Vis spectrophotometric methods and one fluorimetric method have been developed for the quantitative determination of fluoxetine hydrochloride in bulk and pharmaceutical formulations. These methods are based on the ion-pair complex formation between alizarin red $\mathrm{S}$ and fluoxetine hydrochloride. In the first method (method A), the yellow-colored complex obtained in acidic medium was extracted with chloroform and the absorbance of the chloroformic solution was measured at $425 \mathrm{~nm}$. Beer's law limits $(9.5-48 \mu \mathrm{g} / \mathrm{mL})$, the molar absorptivity $\left(5256 \mathrm{~L} \cdot \mathrm{mol}^{-1} \cdot \mathrm{cm}^{-1}\right)$, and the complex composition $(1: 1)$ were determined. In the second method (method B), the yellow complex fluoxetine - alizarin red S extracted in chloroform was broken in alkaline medium, and the absorbance of the resulting violet-colored free dye was measured at $524 \mathrm{~nm}$. A linear relationship was observed in the range of $9.0-54 \mu \mathrm{g} / \mathrm{mL}$. In the third method (method C) the fluorescence intensity of the fluoxetine - alizarin red S complex, obtained in the same manner as for method A, was measured at $594 \mathrm{~nm}$ after excitation at $425 \mathrm{~nm}$. The fluorescence intensity was proportional to the drug concentration in the linear range of $2.7-10.2 \mu \mathrm{g} / \mathrm{mL}$. The limits of detection and quantification have also been calculated. Furthermore, the proposed methods have been successfully applied for the assay of the drug in pharmaceutical dosage forms.
\end{abstract}

Keywords: fluoxetine hydrochloride, spectrophotometry, fluorimetry, ion-pair, alizarin red S

Quality control of pharmaceuticals is mandatory for the assessment of drug safety and efficacy. For this purpose, pharmaceutical analysis requires a rigorous qualitative and quantitative control of drug substances and excipients, both in pure form and in pharmaceutical formulations (1). Hence, pharmaceuticals are suitable for therapeutic use if they are free from impurities and administered in an appropriate amount $(2,3)$.

Fluoxetine hydrochloride (FLX), $(R S)-\mathrm{N}-$ methyl-3-phenyl-3-(4-trifluoromethyl phenoxy)pro-

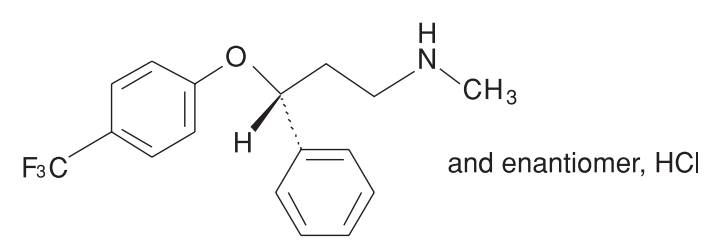

Figure 1. Chemical structure of fluoxetine hydrochloride pan-1-amine hydrochloride (Fig. 1) (4) is a selective serotonin reuptake inhibitor with reduced side effects. FLX is prescribed for the treatment of major depression, obsessive-compulsive disorders or metabolic dysfunctions, anorexia, being one of the most widely prescribed antipsychotic drugs. In addition, FLX is used in the treatment of pain associated with diabetic neuropathy and premenstrual syndrome (5).

Numerous analytical methods have been developed for the assay of FLX in bulk, biological samples and pharmaceutical formulations: chemical (6), electrochemical $(7,8)$, optical (9-17) chromatographic $(6,18-22)$ or capillary electrophoresis methods (23). European Pharmacopoeia reports an HPLC method for the assay of FLX (4).

Due to their sensitivity, speed and simplicity, spectrophotometric and spectrofluorimetric methods have attracted much interest in pharmaceutical analysis. Moreover, most of the additives or excipients found in

\footnotetext{
* Corresponding author: e-mail: ioana.constantinescu @umfcd.ro
} 
pharmaceutical formulations do not exhibit appreciable absorption or fluorescence properties, which represents another advantage of these methods (24).

Extractive spectrophotometric methods are widely used for the assay of pharmaceutical substances, especially in dosage forms. Many of these methods are based on ion-association formation $(25$, 26). Alizarin Red sulfonate, 3,4-Dihydroxy-9,10dioxo-2-anthracenesulfonic acid sodium salt (ARS), has been used as a reagent in the spectrophotometric determination of several metal ions (27) and pharmaceutical substances such as itopride, midodrine, diclofenac, mesalamine and sumatriptan (28), levodopa (29), clomipramine hydrochloride (30), doxepin hydrochloride (31) and haloperidol (32).

To the best of our knowledge, the reaction between ARS and FLX has not yet been investigated. This study aims at using this reaction for the development of new methods (two UV-Vis spectrophotometric and one fluorimetric) for the assay of FLX in bulk and pharmaceutical formulations. Selection of the appropriate experimental conditions is also addressed. The results were compared with those reported for the assay of fluoxetine by other reported methods.

\section{EXPERIMENTAL}

\section{Apparatus}

A Perkin Elmer UV-VIS spectrometer Lambda 2 (Perkin Elmer) (10 mm quartz cells) was used for recording of absorption spectra; fluorescence spectra were recorded on a Jasco FP-6500 spectrofluorimeter (Jasco) (all measurements were performed in quartz cells with $1.0 \times 1.0 \mathrm{~cm}$ path length at $25 \pm$ $1^{\circ} \mathrm{C}$ ); an analytical balance (Mettler Toledo AT261 Delta Range) with a sensitivity of $0.01 \mathrm{mg}$ was used for weighing; $\mathrm{pH}$ measurements were carried out on a Metrohm 716 DMS Titrino equipped with glass combination $\mathrm{pH}$ electrode; an ultrasonic bath Elma 9331-1 (Elma Schmidbauer GmbH) was used for an effective and fast dissolution of samples.

\section{Reagents and materials}

Fluoxetine hydrochloride was kindly supplied by S.C. Vim Spectrum and was used without further purification. Alizarin red S (Fluka AG, Buchs SG) $0.05 \%(\mathrm{w} / \mathrm{v})$ aqueous solution, potassium hydroxide (Merck KGaA) $0.2 \%$ (w/v) ethanolic solution, hydrochloric acid (Merck KGaA) $1 \mathrm{M}$ aqueous solution were obtained by dilution with distilled water or with ethanol (Merck KGaA). Chloroform for spectroscopy Uvasol® (Sigma Aldrich) was used without further purification. Sodium sulfate anhydrous
(Merck KGaA), potato starch (Fluka) and magnesium stearate (Magnesia) were used as received. Double distilled water was used for all experiments. All reagents used in this study were of analytical grade (except for chloroform, which was of spectrophotometric grade). The pharmaceutical formulation Fluoxin capsules $20 \mathrm{mg}$ (S.C.Vim Spectrum) was purchased from the local market and was labeled to contain $20 \mathrm{mg}$ of fluoxetine as $22.36 \mathrm{mg}$ fluoxetine hydrochloride - per capsule.

A stock solution containing $4.75 \mathrm{mg}$ FLX / mL was prepared in distilled water, as follows: an accurately weighted amount of FLX was quantitatively transferred into a $50 \mathrm{~mL}$ calibrated flask, dissolved in $30 \mathrm{~mL}$ water and diluted to the mark with water and stored at $4^{\circ} \mathrm{C}$. Under these conditions, the solution was found to be stable at least two days. The working solution containing $0.24 \mathrm{mg} F L X / \mathrm{mL}$ was prepared daily by suitable dilution of the stock solution in the same solvent.

\section{Methods}

Job's method of continuous variation (33) was employed for the determination of FLX-ARS ionpair stoichiometry. The methods used for FLX determination were validated according to the $\mathrm{ICH}$ regulations Q2 (R1) (34).

\section{Procedure for drug determination}

Method A: Accurately measured 1.0, 1.5, ... $5.0 \mathrm{~mL}$ volumes from the FLX working solution were transferred into a series of $200 \mathrm{~mL}$ separating funnels. To each funnel, $5.0 \mathrm{~mL}$ of $1 \mathrm{M}$ hydrochloric acid solution and $6.0 \mathrm{~mL}$ of $0.05 \%$ ARS were added; the total volume was adjusted to $20 \mathrm{~mL}$ by adding an adequate amount of water. The content of the separating funnel was well mixed and the formed ion-pair complex was extracted into chloroform by vigorously shaking for $2 \mathrm{~min}$, first with $10 \mathrm{~mL}$ chloroform, and then, three times with $5 \mathrm{~mL}$ chloroform. The two phases were allowed to stand for separation. The chloroformic layer was dried over anhydrous sodium sulfate and collected into a $25 \mathrm{~mL}$ volumetric flask. The total volume was adjusted to the mark with chloroform. The absorbance of the yellow ion-pair complex was measured at $425 \mathrm{~nm}$ against a reagent blank. The two phases were allowed to stand for separation. The chloroformic layer was dried over anhydrous sodium sulfate and collected into a $25 \mathrm{~mL}$ volumetric flask. The total volume was adjusted to the mark with chloroform. The absorbance of the yellow ionpair complex was measured at $425 \mathrm{~nm}$ against a reagent blank. 
Method B: Different aliquots of a chloroformic solution of FLX-ARS complex, prepared by following the same procedure described for method A, were transferred into a series of $10 \mathrm{~mL}$ volumetric flasks and the total volume was brought to $9.5 \mathrm{~mL}$ by adding an adequate volume of chloroform. Then, to each flask, $0.5 \mathrm{~mL}$ of $0.2 \%$ ethanolic $\mathrm{KOH}$ was added. The content was mixed and allowed to stand for $50 \mathrm{~min}$. The absorbance of the violet chloroformic solution was measured at $524 \mathrm{~nm}$ against a reagent blank.

Method C: Following the same procedure described for method A, chloroformic solutions of FLX-ARS complex (corresponding to 2.7-10.2 $\mu \mathrm{g}$ FLX $/ \mathrm{mL}$ ) were prepared. The fluorescence intensity of each chloroformic solution was measured at $594 \mathrm{~nm}$ after excitation at $425 \mathrm{~nm}$ using a reagent blank as a reference. The instrument parameters were set as follows: bandwidth (excitation) $5 \mathrm{~nm}$, bandwidth (emission) $5 \mathrm{~nm}$, response $1 \mathrm{sec}$, sensitivity medium, data pitch $1 \mathrm{~nm}$, scanning speed 200 $\mathrm{nm} / \mathrm{min}$.

\section{Procedure for commercial capsules}

The content of 20 capsules was weighed and the average mass was determined; the content of those 20 capsules was mixed and finely powdered. An amount of the powder equivalent to the average mass of capsule contents (corresponding to $20.0 \mathrm{mg}$ fluoxetine or $22.36 \mathrm{mg}$ fluoxetine hydrochloride) was accurately weighed and transferred to a $50 \mathrm{~mL}$ volumetric flask; $30 \mathrm{~mL}$ of water was added, and the suspension was shaken for $15 \mathrm{~min}$ in an ultrasonic bath. The solution was diluted to the mark with water, mixed well and filtered through a Whatman no. 42 filter paper. The first portion of filtrate $(10 \mathrm{~mL})$ was removed, and a suitable aliquot of the filtrate was used for the assay of FLX by the procedures described for methods A, $\mathrm{B}$, and $\mathrm{C}$, respectively.

\section{RESULTS AND DISCUSSION}

The new UV- vis spectrophotometric and fluorimetric methods established for determinations of FLX are based on the ion-pair formation between<smiles>CNCC[C@H](Oc1ccc(C(F)(F)F)cc1)c1ccccc1</smiles><smiles>[CH2+][NH+](C)CC[C@H](Oc1ccc(C(F)(F)F)cc1)c1ccccc1</smiles>

Protonated fluoxetine<smiles>[NH3+]c1ccc2c(c1)C(=O)c1c(cc(S(=O)(=O)O)c(O)c1O)C2=O</smiles>
$+\mathrm{CHCl}_{3}$
$(-\mathrm{NaCl})$<smiles>[1H][NH+](C)CC[C@H](Oc1ccc(C(F)(F)F)cc1)c1ccccc1</smiles>
Alizarin Red S<smiles>O=C1c2ccccc2C(=O)c2c1cc(S(=O)(=O)[O-])c(O)c2O</smiles>

$1: 1$ yellow and fluorescent ion pair complex of FLX-ARS measured at $425 \mathrm{~nm}$ (method A) or at $594 \mathrm{~nm}$ after excitation at $425 \mathrm{~nm}$ (method C)

Scheme 1. The proposed reaction pathway for the ion-pair complex formation 
FLX and alizarin red S, using chloroform as a solvent for the extraction of ion-pair from aqueous solution.

Due to its nitrogen atom, fluoxetine behaves as a base; therefore, in acidic media, it will be found in a cationic form. This high molecular weight, voluminous cation has the ability to form ionic associa- tions with voluminous anions. The alizarin red $\mathrm{S}$ (ARS) aqueous solution has an acidic $\mathrm{pH}$ due to the presence in its structure of the three acidic functional groups: the sulfonic acid group (ionized) and the two $-\mathrm{OH}$ groups (week acidic, $\mathrm{pKa}_{1}=5.5, \mathrm{pKa}_{2}=$ 11) whose ionization depends on the $\mathrm{pH}$ value (35).<smiles>C[NH2+]CC[C@@H](Oc1ccc(C(F)(F)F)cc1)c1ccccc1</smiles><smiles>COS(=O)(=O)c1cc2c(c(O)c1O)C(=O)c1ccccc1C2=O</smiles>

$1: 1$ yellow ion pair complex of FLX-ARS<smiles>CNCC[C@H](Oc1ccc(C(F)(F)F)cc1)c1ccccc1</smiles>

Fluoxetine

Dianionic form of alizarine red $\mathrm{S}$ of violet color measured at $524 \mathrm{~nm}$ (method B)

Scheme 2. The proposed mechanism for the formation of the ARS dianionic form

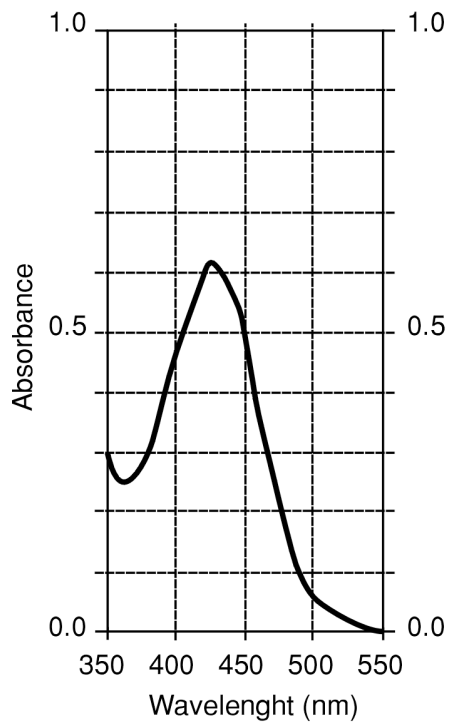

(a)

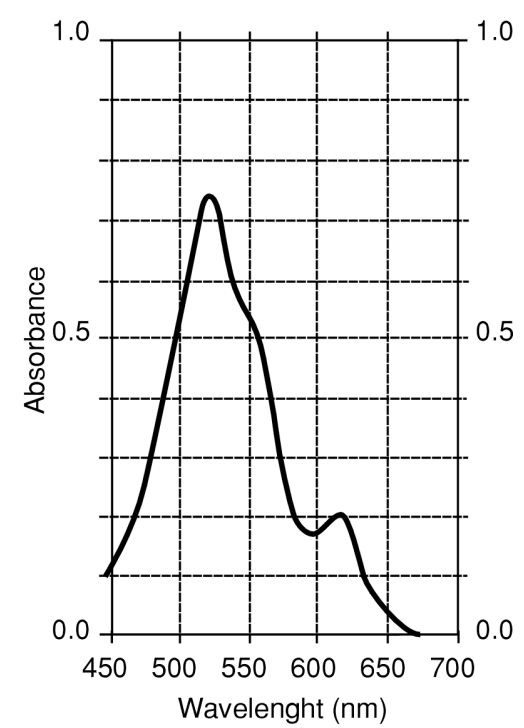

(b)

Figure 2. Absorption spectra of FLX-ARS method A (40 $\mu \mathrm{g}$ FLX/mL), (b) method B (30 $\mu \mathrm{g}$ FLX/mL) 


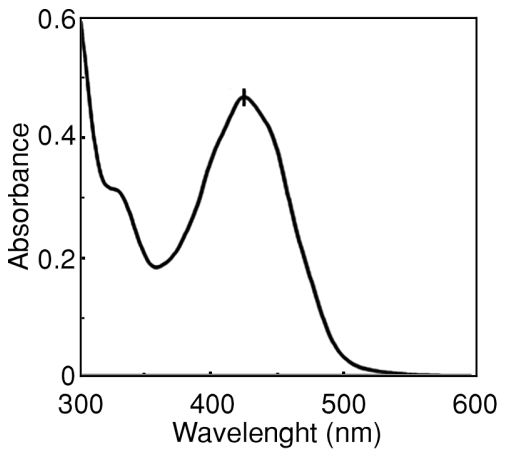

(a)

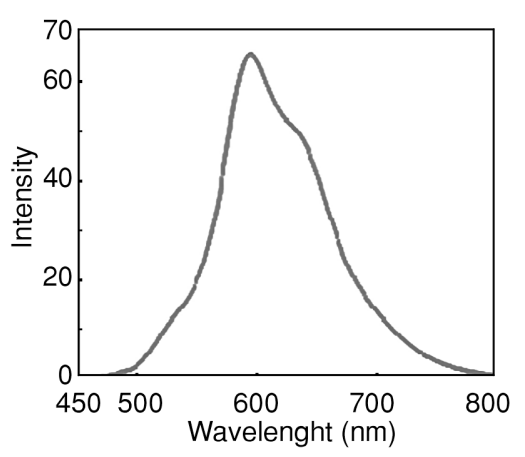

(b)

Figure 3. Excitation (a) and emission (b) spectra of FLX-ARS

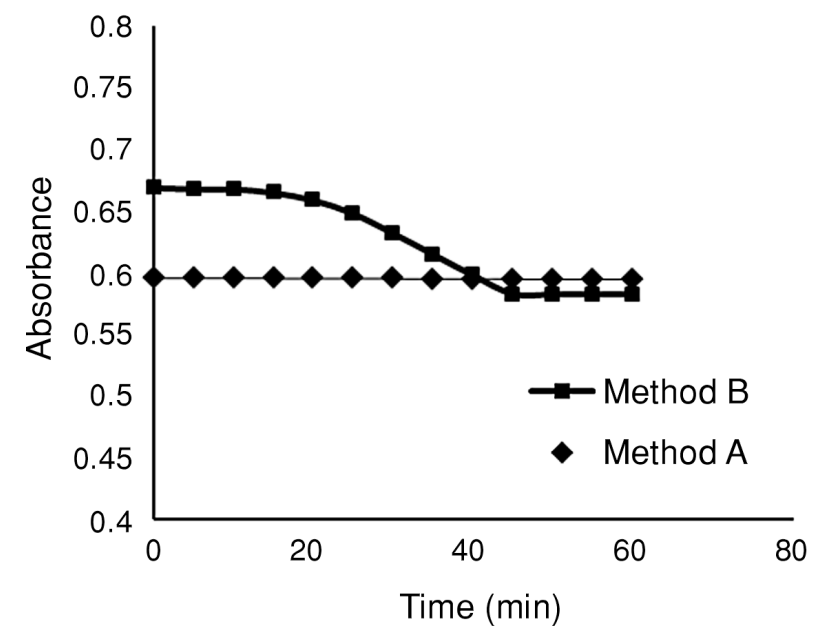

Figure 4. Effect of time on the absorbance ( $40 \mu \mathrm{g}$ FLXmL for method A and $27 \mathrm{mg}$ FLX/mL method B)

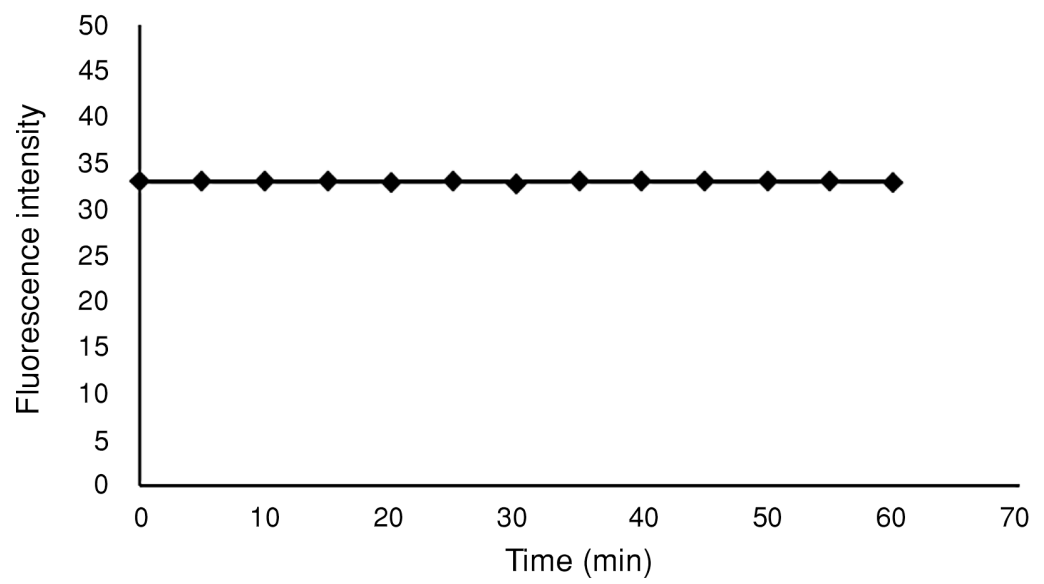

Figure 5. Effect of time on the fluorescence intensity $(10 \mu \mathrm{g} F \mathrm{FL} / \mathrm{mL})$ 


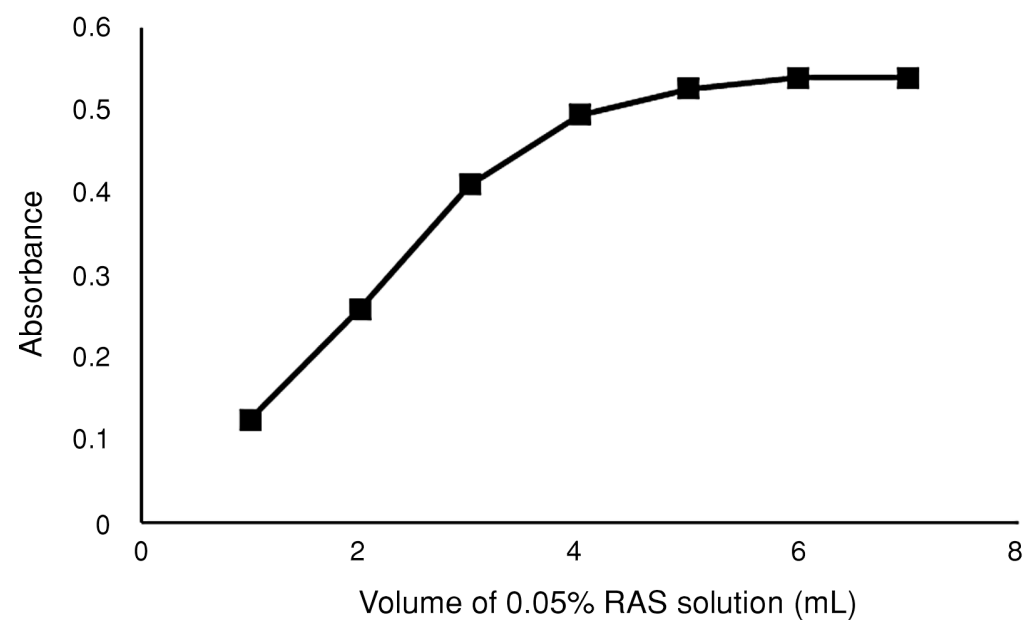

Figure 6. Effect of the ARS concentration on the absorbance value of FLX- ARS ion-pair (3.6 $\mu \mathrm{g}$ FLX/mL)

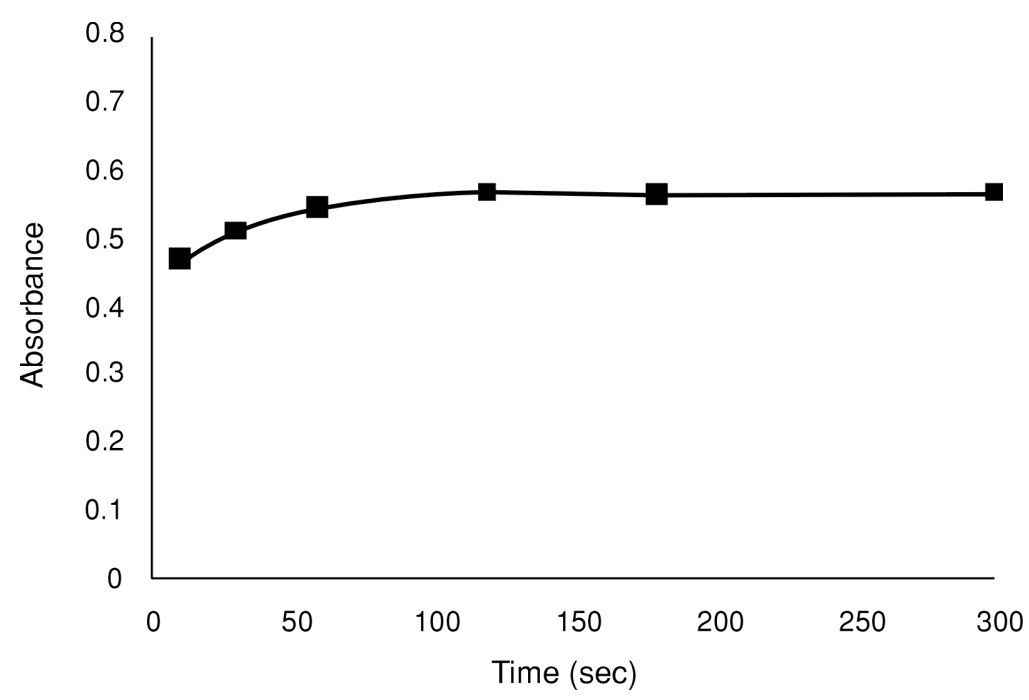

Figure 7. Effect of shaking time ( $36 \mu \mathrm{g} \mathrm{FLX} / \mathrm{mL})$

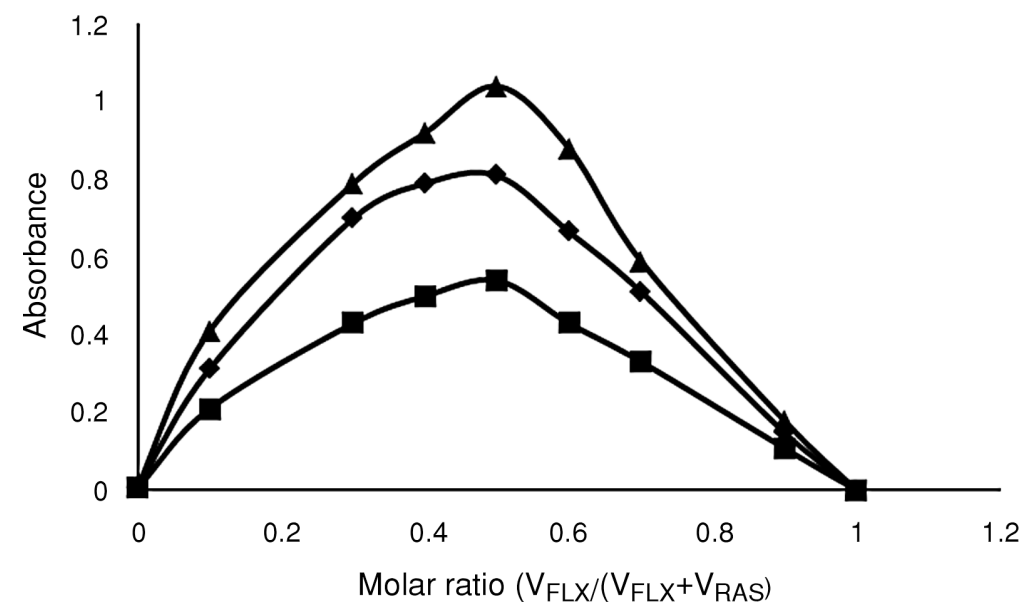

Figure 8. Job's Continuous-variations plots of FLX-ARS ion-pair 
Therefore, at different $\mathrm{pH}$ values, either the molecular form or one of the ionized forms will predominate. The aqueous solutions of alizarin red $\mathrm{S}$, depending on the ionization of the phenolic groups, are yellow at $\mathrm{pH}<5$ and become violet at $\mathrm{pH}>11$, hence exhibiting characteristic absorbances in the visible spectrum.

Following the addition of an ARS solution to an acidic solution of FLX, a yellow ion-pair compound (FLX-ARS) is obtained; this complex was found to be soluble in chloroform. The possible mechanism for the formation of the ion-pair complex is given in Scheme 1. The ion-pair is unstable in alkaline medium; therefore, the complex is broken and the resulting free alizarin red $\mathrm{S}$ dianion causes the solution to be colored in violet. Method A involves the measurement of the absorbance value corresponding to the yellow chloroformic solution. Method B, on the other hand, measures the absorbance of the violet chloroformic solution; the mechanism proposed for the formation of the ARS dianionic form (method B) is given in Scheme 2. Moreover, the bathochromic shift of the absorption maximum from the UV spectral region to the visible spectrum, allowed these procedures to be interference-free.

FLX does not display native fluorescence; in order to render its fluorimetric determination possible, conversion to a suitable derivative was mandatory. For this reason, ARS, a fluorogenic reagent, was chosen, and the ion-pair FLX-ARS was found to be adequate for further fluorescence determinations.

\section{Selection of the extracting solvent and wave- length}

Several organic solvents (chloroform, carbon tetrachloride, dichloromethane) have been tested for

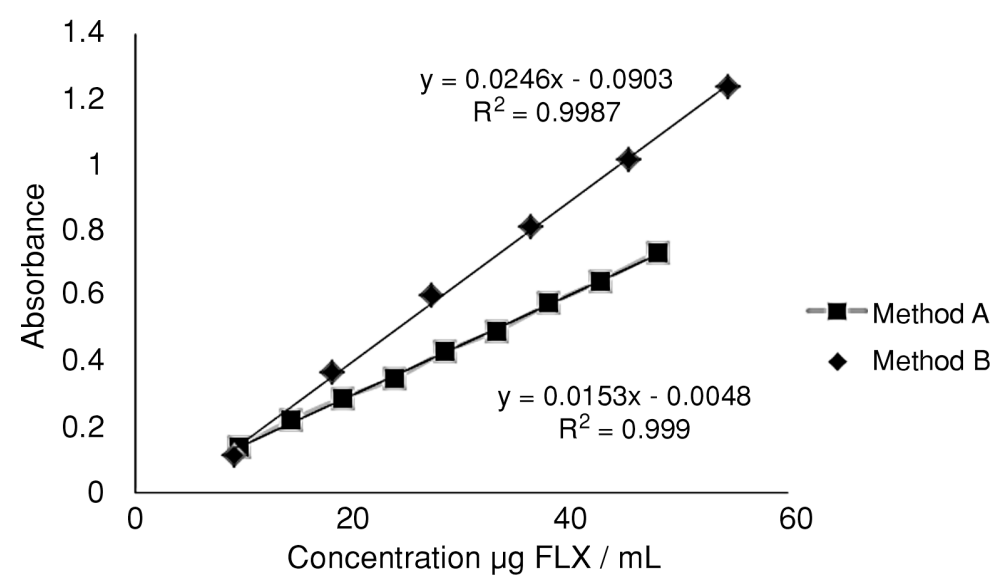

Figure 9. Calibration curves for determination of FLX by the proposed methods (method A and method B)

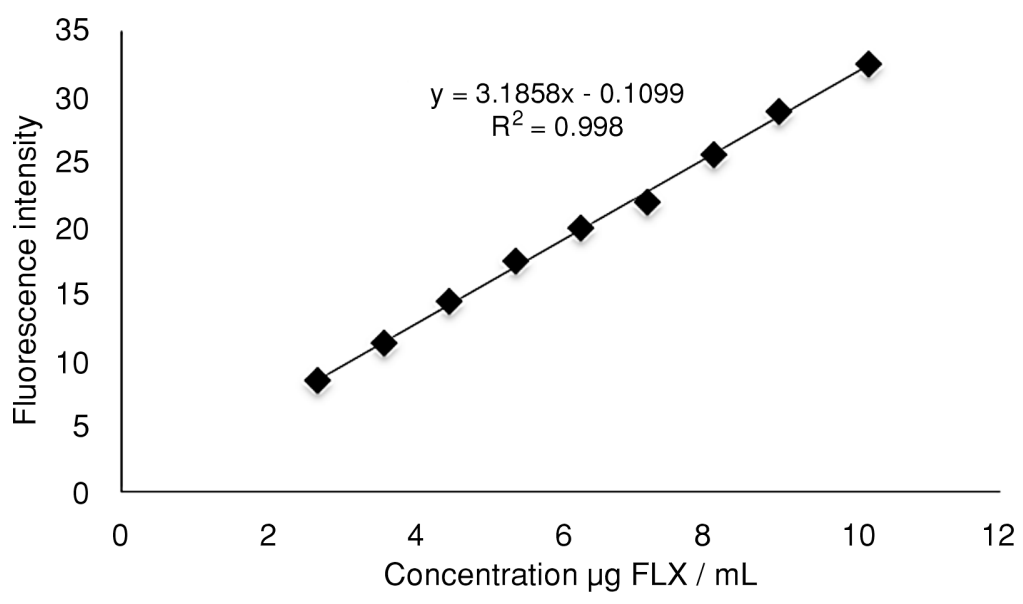

Figure 10. Calibration curves for determination of FLX by the proposed method C 
the extraction of the ion-pair from the aqueous phase. Chloroform was selected based on its highest extraction efficacy of the ion association from the aqueous phase (correlated with the highest fluorescence intensity). The dissociation is reduced and the existence of the ion-pair is ensured in chloroform.

The absorption spectrum was recorded against a reference blank and it was found that the ion-pair exhibits an absorption maximum at $\lambda=425 \mathrm{~nm}$ (method A) (Fig. 2). For method B, the solution shows a maximum of absorbance at $\lambda=524 \mathrm{~nm}$ (Fig. 2). Consequently, these two wavelength values were chosen for subsequent measurements included in the proposed UV-VIS methods. After excitation at $425 \mathrm{~nm}$, the fluorescence spectrum showed a maximum of fluorescence intensity at $594 \mathrm{~nm}$, due to the presence of ARS (Fig. 3).

The effect of time on the stability of the chromophore or fluorophore groups was studied by measuring the absorbance of a chloroformic solution, at 10-minute time intervals, at $425 \mathrm{~nm}$ (method A) and $524 \mathrm{~nm}$ (method B), respectively, against a reagent blank, and by measuring the fluorescence intensity for a chloroformic solution at $594 \mathrm{~nm}$ after excitation at $425 \mathrm{~nm}$ (method $\mathrm{C}$ ). The absorbance values remain constant for at least $1 \mathrm{~h}$ for method $\mathrm{A}$ (Fig. 4) or method C (Fig. 5). This allows the analysis of a large number of samples. For method B, the value of absorbance decreases in the first $40 \mathrm{~min}$, then remains constant (Fig. 4). For this reason, the absorbance reading was performed after $50 \mathrm{~min}$.

\section{Optimization of the methods}

In order to achieve a complete reaction, highest sensitivity and maximum absorbance or fluorescence intensity, the effects of the ARS concentration, $\mathrm{HCl}$ volume and shaking time were investigated.

The effect of the ARS concentration was studied by measuring the absorbance of the organic phases after extraction from aqueous solutions containing a fixed concentration of FLX and varied amounts of dye at acidic $\mathrm{pH}<1$. The volume of the aqueous solutions was maintained constant at $20 \mathrm{~mL}$ by adding various volumes of distilled water. It was observed that the absorbance increases with the increasing volume of the ARS solution. It was found that the maximum color intensity and maximum absorbance were achieved with $6 \mathrm{~mL}$ ARS $0.05 \%$ solution that provided an excess of dye (Fig. 6).

The effect of the shaking time revealed that the maximum absorbance value was reached after $2 \mathrm{~min}$ of shaking for the first step of the extraction (Fig. 7).

Stoichiometric relationship: For the determination of the molar ratio, Job`s method of continuous variation of equimolar solutions was used. Three series of solutions in which the total volume of FLX and ARS was kept at $10 \mathrm{~mL}$ were prepared, using three series of standard FLX solutions (1.0 $10^{-}$

Table 1. Assay parameters and validation criteria for FLX determination by the proposed methods.

\begin{tabular}{|c|c|c|c|}
\hline \multirow{2}{*}{$\begin{array}{l}\text { Parameter/ } \\
\text { Validation criteria }\end{array}$} & \multicolumn{3}{|c|}{ Value } \\
\hline & Method A & Method B & Method C \\
\hline Wavelength (nm) & 425 & 524 & $\begin{array}{l}594 \mathrm{~nm} \text {-emission } \\
425 \mathrm{~nm} \text { - excitation }\end{array}$ \\
\hline Linearity range $(\mu \mathrm{g} / \mathrm{mL}) *$ & $9.5-48$ & $9-54$ & $2.7-10.2$ \\
\hline $\begin{array}{l}\text { Molar absorbtivity, } \varepsilon \\
\left(\mathrm{L} \cdot \mathrm{mol}^{-1} \cdot \mathrm{cm}^{-1}\right)\end{array}$ & 5256 & 7654 & - \\
\hline $\mathrm{A}_{\mathrm{lcm}}^{1 \%}$ & 153 & 246 & - \\
\hline Regression equation (y) & $0.0153 x-0.0048$ & $0.0246 x-0.0903$ & $3.1858 x-0.1099$ \\
\hline Correlation coefficient (r) & 0.9995 & 0.9993 & 0.9990 \\
\hline Standard deviation of slope & 0.00019 & 0.00044 & 0.05379 \\
\hline Standard deviation of intercept & 0.01755 & 0.01578 & 0.36115 \\
\hline $\mathrm{LOD}(\mu \mathrm{g} / \mathrm{mL})$ & 0.12 & 0.13 & 0.013 \\
\hline LOQ $(\mu \mathrm{g} / \mathrm{mL})$ & 0.36 & 0.41 & 0.040 \\
\hline $\begin{array}{l}\text { Accuracy (Confidence range for } \\
95 \% \text { level of confidence) }\end{array}$ & $99.45 \pm 0.75$ & $100.72 \pm 0.38$ & $100.68 \pm 0.45$ \\
\hline Repeatability (R.S.D. \%) & 0.69 & 0.81 & 0.85 \\
\hline Intermediate precision (R.S.D. \%) & 0.95 & 1.22 & 1.17 \\
\hline
\end{tabular}

$* \mathrm{~N}=9$ (methods A and $\mathrm{C}), \mathrm{N}=6$ (method $\mathrm{B})$ (the number of calibration level), $\mathrm{n}=3$ (the number of replicates at each level) 
Table 2. Comparison of the proposed methods with other existing methods for the determination of fluoxetine hydrochloride.

\begin{tabular}{|c|c|c|c|c|c|}
\hline Reagent & $\begin{array}{l}\text { Linear range } \\
(\mu \mathrm{g} / \mathrm{mL})\end{array}$ & $\begin{array}{c}\text { LOD } \\
(\mu \mathrm{g} / \mathrm{mL})\end{array}$ & $\begin{array}{c}\text { LOQ } \\
(\mu \mathrm{g} / \mathrm{mL})\end{array}$ & $\mathrm{RSD} \%$ & Reference \\
\hline \multicolumn{6}{|c|}{ Spectrophotometric methods } \\
\hline Alizarin red $\mathrm{S}$ & $9.5-48$ & 0.12 & 0.36 & $0.69-0.95$ & Proposed method A \\
\hline Alizarin red $\mathrm{S}$ & $9-54$ & 0.13 & 0.41 & $0.81-1.22$ & Proposed method B \\
\hline $\begin{array}{l}\text { Benzoyl peroxide and } \\
\text { potassium iodide }\end{array}$ & $10-2000$ & 10 & - & 0.68 & (12) \\
\hline Orange II & $0.2-9.0$ & 0.17 & - & $0.022-0.038$ & (13) \\
\hline Chrome azurol S & $5-50$ & - & - & 1.64 & (14) \\
\hline $\begin{array}{l}\text { Base hydrolysis and } \\
\text { reaction of methylamine } \\
\text { with sodium nitroprusside }\end{array}$ & $0.5-25$ & $0.15 \pm 0.01$ & $0.29 \pm 0.03$ & 7.9 & (15) \\
\hline Metanil yellow & $1.01-10.14$ & 0.44 & 1.34 & $0.49-0.60$ & (11) \\
\hline $\begin{array}{l}\text { Bromate-bromide mixture } \\
\text { and methyl orange }\end{array}$ & $0.4-12$ & 0.32 & 1.0 & 2.04 & (16) \\
\hline $\begin{array}{l}\text { 1,2-naphthoquinone-4- } \\
\text { sulphonate }\end{array}$ & $0.3-6$ & 0.1 & 0.3 & 1.52 & (17) \\
\hline \multicolumn{6}{|c|}{ Fluorimetric methods } \\
\hline Alizarin red $\mathrm{S}$ & $2.7-10.2$ & 0.013 & 0.040 & $0.85-1.17$ & Proposed method C \\
\hline $\begin{array}{l}\text { 4-chloro-7- } \\
\text { nitrobenzo-2-oxa- } \\
\text { 1,3-diazolex }\end{array}$ & $0.5-25$ & $0.15 \pm 0.01$ & $0.29 \pm 0.03$ & 7.9 & (15) \\
\hline
\end{tabular}

Table 3. Data for the pharmaceutical assay.

\begin{tabular}{|c|c|c|c|}
\hline Data & Method A & Method B & Method C \\
\hline Mean recovery $(\%)$ & 100.05 & 99.05 & 98.76 \\
\hline Confidence range $(\%) *$ & $100.05 \pm 0.85$ & $99.05 \pm 1.04$ & $98.76 \pm 0.45$ \\
\hline
\end{tabular}

$* \mathrm{n}=3$ (the number of replicates at each level)

${ }^{3} \mathrm{M} ; 1.5 \cdot 10^{-3} \mathrm{M}$ and $\left.2.0 \cdot 10^{-3} \mathrm{M}\right)$ and three series of ARS solutions $\left(1.0 \cdot 10^{-3} \mathrm{M} ; 1.5 \cdot 10^{-3} \mathrm{M}\right.$ and $2.0 \cdot 10^{-3}$ $\mathrm{M})$. After extraction in chloroform, the measurements of absorbance were made at $425 \mathrm{~nm}$, against a reagent blank. The maximum value of the absorbance was found for a [FLX] / ([FLX-ARS] + [ARS]) ratio of 0.5 (Fig. 8).

Results indicate that $1: 1$ (FLX: ARS) ion-pair was formed through the electrostatic attraction between the positive protonated $\mathrm{FLX}^{+}$and the negative anionic ARS. The extraction equilibrium of FLX-ARS between the two phases can be represented as follows:

$$
\begin{gathered}
\mathrm{FLX}_{(\mathrm{aq})}^{+}+\mathrm{ARS}_{(\mathrm{aq})} \leftrightarrows \mathrm{FLX}^{+} \cdot \mathrm{ARS}_{(\mathrm{aq})}^{-} \leftrightarrows \\
\mathrm{FLX}^{+} \cdot \mathrm{ARS}_{\text {(chloroform) }}^{-}
\end{gathered}
$$

The conditional stability constant $\left(\mathrm{K}_{\mathrm{f}}\right)$ of the ion-pair complex FLX-ARS was calculated from the experimental data obtained from the continuous variation method using the following equation (36):

$$
\mathrm{K}_{\mathrm{t}}=\frac{\mathrm{A} / \mathrm{A}_{\mathrm{m}}}{\left[1-\mathrm{A} / \mathrm{A}_{\mathrm{m}}\right]^{\mathrm{n}+2} \mathrm{CM}(\mathrm{n})^{\mathrm{n}}}
$$

(A and $A_{m}$ are the observed maximum absorbance and the absorbance value when all the present drug is associated, respectively; $C_{M}$ is the molar concentration of the drug at the maximum absorbance and $\mathrm{n}$ is the ratio in which the dye ion associates with the drug). The value obtained for $\log$ $\mathrm{K}_{\mathrm{f}}$ was $4.235 \pm 0.003$.

\section{Methods validation}

Linearity: Standard calibration curves were constructed by plotting the absorbance values (at $425 \mathrm{~nm}$ for method A or at $524 \mathrm{~nm}$ for method B) versus concentration of FLX and the fluorescence intensity versus concentration of FLX (method C). Linear correlations were found between absorbance and concentration of FLX in the concentration range of $9.5-48 \mu \mathrm{g} / \mathrm{mL}$ (method A) and $9-54 \mu \mathrm{g} / \mathrm{mL}$ (method B). For the fluorimetric method, under the reaction conditions, a good linear relationship was found between the fluorescence intensity and concentration in the range of $2.7-10.2 \mu \mathrm{g} F \mathrm{FL} / \mathrm{mL}$. 
These linear correlations were described by the regression equations, $\mathrm{y}=0.0153 \mathrm{x}-0.0048$ (method A), $\mathrm{y}=0.0246 \mathrm{x}-0.0903(\operatorname{method} \mathrm{B})$ and $\mathrm{y}=$ $3.1858 \mathrm{x}-0.1099$ (method C). The linearity of the calibration curves in the studied concentration ranges was proved by the correlation coefficients, which were found to be $0.9995(\operatorname{method}$ A) (Fig. 9), 0.9993 (method B) (Fig. 9) and 0.9990 (method C) (Fig. 10), respectively.

Sensitivity was evaluated by calculating the limit of detection (LOD) and limit of quantification (LOQ) for the proposed methods using the following equations (23):

$$
\mathrm{LOD}=\frac{3.3 \cdot \mathrm{s}}{\mathrm{k}} \quad \mathrm{LOD}=\frac{10 \cdot \mathrm{s}}{\mathrm{k}}
$$

where $s$ is the standard deviation of three replicate values under the same conditions as for the sample analysis in the absence of the analyte and $k$ is the sensitivity (the slope of the calibration curve). The values of LOD and LOQ for all three proposed methods were calculated (Table 1)

Accuracy of these three methods was evaluated. Samples of known concentrations of FLX (concentrations of 80,100 and $120 \%$ of the value of interest) were prepared. For each solution, the maximum value of absorbance or fluorescence intensity of the chloroformic solutions was recorded against blank. Then, FLX concentrations were calculated using the regression equations. The statistical analysis of the results is presented in Table 1.

Precision of the three methods was determined in terms of repeatability (intraday) and intermediate precision (inter-day). Three different concentrations of FLX were analyzed in three independent series during the same day (intraday precision) and three consecutive days (inter-day precision), respectively. FLX concentrations were calculated using the linear regression equations. The relative standard deviations were also calculated (Table 1).

Table 1 shows the data obtained for the methods validation.

Assay parameters are similar or superior to those obtained for the determination of fluoxetine hydrochloride by other spectrophotometric and fluorimetric methods (Table 2).

\section{Analysis of the pharmaceutical formulations}

The proposed methods were successfully applied to the determination of FLX in dosage forms. Mean recoveries of FLX from $20 \mathrm{mg}$ Fluoxin capsules and confidence ranges were calculated and the results were in good agreement with the label claims (Table 3). The selectivity of these methods was evaluated by applying it to a synthetic mixture containing fluoxetine hydrochloride and adjuvants from Fluoxin capsules $(22.3 \mathrm{mg}$ fluoxetine hydrochloride, $40 \mathrm{mg}$ magnesium stearate, and $30 \mathrm{mg}$ potato starch). No interference was observed from these excipients in the pharmaceutical dosage forms of FLX, indicating the high selectivity of these methods for the drug substance.

\section{CONCLUSIONS}

These three proposed methods are simpler and more cost-effective compared to the previously reported chromatographic methods. The reagents used in the proposed methods are cheaper, readily available and the procedures do not involve any critical reaction. The methods are unaffected by slight variations in experimental conditions, are accurate, reproducible, adequately sensitive and free from interference by excipients. These aspects are of major interest in analytical pharmacy, rendering the assay of fluoxetine in its pharmaceutical dosage forms possible. These methods are suitable for routine analysis either in its pure bulk powder or in pharmaceutical formulations without any preliminary separation step. Assay parameters of the proposed methods are similar or superior to those obtained for the determination of fluoxetine hydrochloride by other spectrophotometric and fluorimetric methods.

\section{REFERENCES}

1. Siddiqui M.R., Al Othman Z.A., Rahman N.: Arabian J. Chem. 10, S1409 (2017).

2. Alothman Z.A., Rahman N., Siddiqui M.R.: Rev. Adv. Sci. Eng. 2, 166 (2013).

3. Rahman N., Azmi S.N.H., Wu H. F.: Accred. Qual. Assur. 11, 69 (2006).

4. ***European Pharmacopoeia, $8^{\text {th }}$ Edition, EDQM, Council of Europe, 67075, Strasbourg Cedex, France 2013.

5. Whalen K.: Lippincott Illustrated Reviews. Pharmacology, $6^{\text {th }}$ Ed., pp. 135-137, Wolters Kluwer International Edition 2012.

6. Bueno F., Bergold A.M., Fröehlich P.E.: Boll. Chim. Farm. 139, 256 (2000).

7. Hussien E.M., Abdel-Gawad F.M., Issa Y.M.: Biochem. Eng. J. 53, 210 (2011).

8. Alizadeh T., Azizi S.: Biosens. Bioelectron. 81, 198 (2016).

9. Nezhadali A., Motlagh M.O., Sadeghzadeh S.: Spectrochim. Acta A Mol. Biomol. Spectrosc. 190, 181 (2018).

10. Ali E.A., Adawy A.M., El-Shahat M.F., Amin A.S.: Egypt. J. Forensic Sci. 6, 370 (2016). 
11. Constantinescu I.C., Florea M., Neagu A.F.: Farmacia 63, 816 (2015).

12. Khan I.U., Aman T., Iqbal M.A., Kazi A.A.: Mikrochim. Acta 134, 27 (2000).

13. Parham H., Pourreza N., Shafiekhani H.: J. Anal. Chem. 63, 626 (2008).

14. Starczewska B., Mielech K.: J. Pharm. Biomed. Anal. 23, 243 (2000).

15. Shah J., Jan M.R., Rehman F.: J. Chil. Chem. Soc. 53, 1605 (2008).

16. Shah J., Jan M., Khan M.N., Durrani S.: Am. J. Analyt. Chem. 3, 828 (2012).

17. Darwish I.A., Amer M.S., Abdine H.H, AlRayes I.L.: Int. J. Anal. Chem. Article ID 257306, 9 pages (2009).

18. Lopes B.R., Cassiano N.M., Carvalho D.M., Moises E.C.D., Cass Q.B: J. Pharm. Biomed. Anal. 150, 362 (2018).

19. Berzas J. J., Guiberteau C., Contento A.M., Rodriguez V.: Chromatographia 56, 545 (2002).

20. da Silva A.C.C., Raasch J.R., Vargas T.G., Peteffi G.P., Hahn R.Z., Antunes M.V., Perassolo M.S., Linden R.: Clin. Biochem. 52. 85 (2018).

21. de Freitas D.F., Porto C.E., Vieira E.P., de Siqueira M.E.: J. Pharm. Biomed. Anal. 51, 170 (2010).

22. Alves V., Goncalves J., Conceicao C., Teixeira H.M., Camara J.S.: J. Chromatogr. A, 1408, 30 (2015).

23. Carcu-Dobrin M., Budau M., Hancu G., Gagyi Laslo, Rusu A., Kelemen H.: Saudi Pharm. J. 25, 397 (2017).

24. Syeda A., Mahesh H.R, Syed A.A.: II Farmaco 60, 47 (2005).
25. Eldidamony A., Hafeez S.M.: Int. J. Pharm. Pharm. Sci. 7, 152 (2015).

26. Neagu A. F., Constantinescu I.C., Nedelcu A., Florea M.: Farmacia 56, 42 (2008).

27. Ullah M.R., Haque M.E.: J. Chem. Eng. 25, 1 (2010).

28. Nair S.G., Shah J. V., Shah P.A., Sanyal M., Shrivastav P.S.: Eurasian J. Anal. Chem. 10, 68 (2015).

29. Basheir B.E.A., Elbashir A.A., Aboul-Enein H.Y.: Rev. Roum. Chim. 60, 555 (2015).

30. Rahman N., Afaq N.: Anal. Methods 2, 513 (2010).

31. Rahman N., Khatoon A.: Arabian J. Chem. 9, S1177 (2016).

32. Rahman N., Siddiqui S.: Drug Test Anal. 2, 252 (2010)

33. Job P.: Annali di Chimica Applicata 9, 113 (1928)

34. ***Validation of Analytical Procedures: Text and Methodology Q2(R1), ICH Harmonised Tripartite Guideline, International Conference on Harmonization of Technical Requirements for Registration of Pharmaceuticals for Humane Use Q2(R1), Current Step 4 version, Geneva, Switzerland 2005.

35. Sabnis R.W.: Alizarin Red S in Handbook of Acid-Base indicators, pp. 14-17, CRC Press (Taylor and Francis Group), Boca Raton, Florida 2007.

36. Inczedy J.: Analytical Applications of Complex Equilibria, p. 137, Ellis Horwood Ltd., UK 1976.

37. Miller J.C., Miller J.N.: Chapter 3. Significance tests in Statistics in Analytical Chemistry, third ed., Ellis Horwood, Chichester 1993.

Received: 14.03. 2018 